\title{
God's Own Tourism: Creating Socio-economic, cultural, and Environmental Sustainability in Tourism Industries in Kerala
}

\author{
K Paul Thomas, \\ PhD Scholar, School of Management Studies, VELS Institute of Science, Technology and Advanced Studies \\ Email: paul@esafbank.com \\ Dr.Rajini.G,
}

Professor \& Head /MBA (Integrated), School of Management Studies, VELS Institute of Science, and Technology

\begin{abstract}
Worldwide governments have recognized tourism as a sector with immense potential for economic development and employment generation. Various international agencies like World Tourism Organization (WTO) have pointed out the vast developmental potential of tourism, particularly regarding the developing nations like India. Despite the wide recognition of the vast developmental potential of tourism, there are growing apprehensions regarding the sustainability of tourism as a development paradigm. The development of tourism induces changes in the social character of a destination. These transformations include the impact of tourism development and its economic efficiency on inhabitants' traditional values, lifestyles, and interpersonal relationships.
\end{abstract}

This also adversely affects the environment, and the industry growingly believes that sustainable tourism alone can provide for stable development in the long run.

Keywords: Tourism; Ecotourism; Sustainability.

\section{Introduction}

Sustainable development is a concept of global development in the 21st century that aims to integrate financial growth with social and environmental stability. It is essential to look at all aspects of development while thinking of business growth to respect natural laws and ensure survival of the planet and therefore accepted by governments of all countries of the world. It reflects the harmonization of needs of economic development and the necessity of environmental protection, carried out to preserve sufficient quantity of natural resources, thus enabling future generations to live and satisfy their own needs. We focus on integrating environmental, social and economic interests, so it is not just about "green" issues.

The link between tourism and sustainable development is more than obvious because of following two facts: tourism is one of the most powerful industries in the world and the main "resources" that it uses in its development are the most beautiful natural, cultural and historical places in the world. Therefore, the share of tourism in global economic and business trends is extremely high, as well as its impact on the state and quality of life in local communities that tourist areas. Mass tourism often substantially endangers or destroys the natural habitat, pollutes water or soil, produces excessive noise, inadequately responds to the needs of the local population and impairs their quality of life because it does not consider the specifics of their tradition, culture, religion. Sustainable tourism balances economic development against the limitations imposed by the environment and the needs of the local population.

\subsection{Defining sustainable tourism}

The United Nations World Tourism Organization defines sustainable tourism as tourism that meets the needs of present tourists and host regions while protecting and enhancing opportunity for the future. Rather than being a type of product, it is an ethos that underpins all tourism activities. It is integral to all aspects of tourism development and management rather than being an add-on component. The aim of sustainable tourism is to keep the economic and social advantages of tourism development while reducing or mitigating any undesirable effects 
on the natural, historic, cultural or social environment. We achieve this by balancing the needs of tourists with those of the destination.

Sustainable tourism development meets the needs of present tourists and host regions while protecting and enhancing opportunities for the future. We envisage it as leading to management of all resources in such a way that economic, social and aesthetic needs can be fulfilled while maintaining cultural integrity, essential ecological processes, biological diversity, and life support systems. While tourism is welcomed almost universally for the benefits and opportunities it creates, there is a growing recognition of the need to see tourism in its environmental context, to acknowledge that tourism and the environment are interdependent, and to work to reinforce the positive relationship between tourists, the environment and poverty reduction.

When we talk about sustainable development, the easiest definition is what we, the present generation, have inherited a certain amount of ecology and environment surrounding in terms of land, water, and air; when we leave it to the next generation, we should leave it at least in the same condition, if not in a better condition than what we inherited. This is the sum and substance of sustainable development, putting it in elementary terms."

Sustainable tourism dissociates itself as a matter of principle from mass tourism and partially associates to alternative, contemporary (post-mass) tourism forms. Sustainable tourism is primarily the opposite of mass tourism. Journal of Sustainable Tourism, 1993, defines this as a positive approach intending to reduce tensions and frictions created by the complexity of interactions between tourism industry, tourist, natural environment and the local communities as host of tourist."

\subsection{Principles of sustainable tourism}

Sustainable tourism is a form of alternative tourism based on the following principles:

a) minimizing the impact of tourism activity on the environment in order to gain ecological sustainability, by contributing to maintaining and enhancement of conservation through the return of a part of the revenues towards the protected area. Practicing tourism forms that do not affect the environment.

b) minimizing the negative impact of tourism activity on the local community and its members to get social sustainability. Developing of those forms of tourism that do not upset and disturb the daily life of the population at the tourist destination.

c) minimizing the negative impact of tourism activity on the culture/traditions/customs of the local communities to get cultural sustainability. Developing a tourism capable of determining the authenticity and individuality of local cultures to be preserved and avoid their saturation with 'external' cultural influences.

d) maximizing the economic benefits of the local population because of developing tourism to achieve economic sustainability. One of the most important principles of sustainable tourism meant to serve the protection and economic development of local communities and protected areas.

e) education, preparation, information. Educating the tourist through a superior awareness and consideration of the impact generated by him, to improve personal attitude towards the environment and reducing the impact. This includes an ecological education component (for visitors, locals, local administration, rural and urban population) that is crucial besides the interpretation component, at the eco-tourism level, both from the point of view of the product and of the local administrations.

f) local control-a basic principle in sustainable tourism. Local community takes part and has a say regarding everything involving sustainable tourism development, and it is an active decision factor. The key element here is local propriety on tourism infrastructure elements (e.g., accommodation structures) and others. Local community and local administrations will be involved, and they have the control, through its financial levers.

\section{Dimensions of sustainable tourism}

\section{Dimensions of Sustainability}


In 2000, the Earth Charter broadened the definition of sustainability to include the idea of a global society "founded on respect for nature, universal human rights, economic justice, and a culture of peace." The 2005 World Summit on Social Development identified sustainable development goals, such as economic development, social development, and environmental protection. The three pillars or dimensions of Sustainability came up in figure 1.

\section{A. Environmental sustainability}

Ecological integrity is maintained, all of earth's environmental systems are kept in balance while natural resources within them are consumed by humans at a rate where they can replenish themselves.

\section{B. Social sustainability}

A socially sustainable society is one in which all members have equal rights, all share equitably in societal benefits, and all take part equally in the decision-making process. Universal human rights and necessities are attainable by all people, who have access to enough resources in order to keep their families and communities healthy and secure.

\section{Economic sustainability}

Economic sustainability considers the social and ecological consequences of economic activity. It incorporates new paradigms like circular economy, cradle to grave, etc. Economic sustainability also means that human communities across the globe can maintain their independence and have access to the resources that they require, financial and other, to meet their needs.

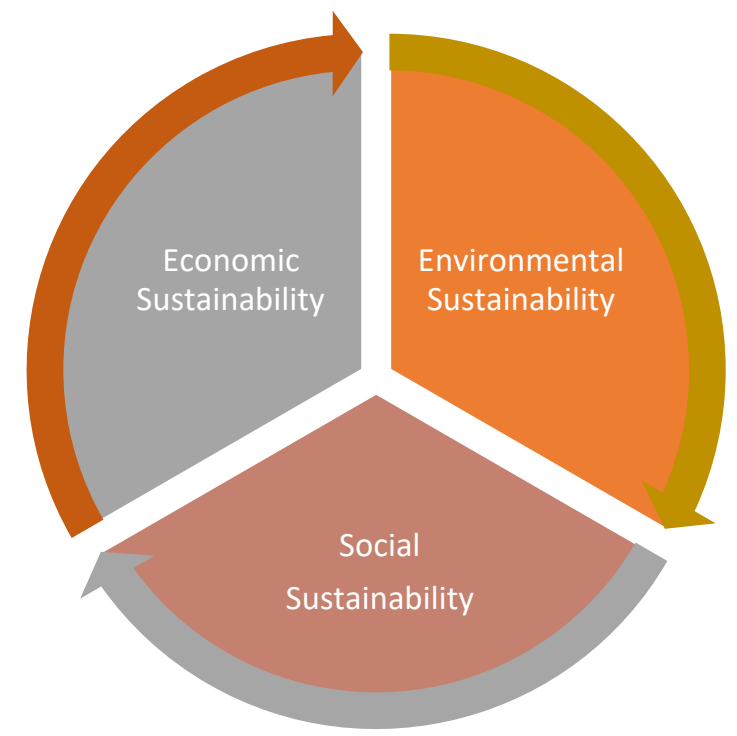

Fig 1: The three pillars or dimensions of Sustainability

\section{History of tourism in Kerala}

Kerala launched its tourism development programs with the establishment of the international beach resort in Kovalam in 1976, with central government patronage. In the 1980s, the state government started Kerala tourism as a hospitality department. Recognizing the huge economic potential of tourism in the state, the government declared tourism as an industry, vide an order dated July 11, 1986. Since then, the state government has extended several incentives, which were available to the investors in other industrial sectors, to the tourism sector, aimed at creating an investment-friendly atmosphere for tourism. 
The Tourism Department formed in 1958 renamed as the Department of Tourism in 1981 is the government agency responsible for the promotion, planning and development of tourism in the state. The infrastructure development schemes were implemented through line departments such as Irrigation Department, Public Works Department, Central Public Works Department and through Public Sector Units (PSUs) such as Kerala Tourism Development Corporation Ltd (KTDC), Kerala Industrial Technical Consultancy Organization (KITCO), Kerala Tourism Infrastructure Ltd (KTIL), Bekal Resorts Development Corporation Ltd (BRDC).

The Department of Tourism assists the District Tourism Promotion Councils (DTPCs) in all the districts for the execution of these projects. The department asserts that DTPCs are the source of specific district wise local information related to all destinations in a district. Main lending institutions like Kerala Financial Corporation (KFC), Travel Financial Corporation of India (TFCI) and Kerala State Industrial Development Corporation (KSIDC) play an important role in funding tourism projects in the state. The stakeholders from the private sector in tourism include tour operators, hotels, resorts, homestays, and houseboat entrepreneurs and the associations related to these concerns.

Kerala government announced first tourism policy of Kerala in 1995, which remains the basis for much of the state's progress in terms of infrastructure, tourism development and product performance. They identified the key role played by the private sector in all these areas besides defining the role of the state as a facilitator, creating a suitable condition for investments by setting up the basic infrastructure for tourism to grow. The policy focused on public-private partnership (PPP) for tapping the tourism potential of the state and thus making it an ideal instrument for social and economic growth. Based on the tourism policy, they held the first Kerala Travel Mart in the state as a public-private partnership in 2000. The Kerala Travel Mart is an annual trade show, wherein the state hosts tour operators and media from Kerala Tourism - The Role of the Government and Economic affects 6 around 50 to 60 countries, and buyers and sellers directly interact to close deals and packages.

Tourism Vision 2025, the policy document prepared by the Department of Tourism and approved by the State Government in 2002, is aimed at making tourism in the state a private sector activity with the state playing the role of a catalyst and facilitator. The government asserts that its focus is on the development of basic infrastructure for the promotion of new tourism products for tapping the tourism potential of Kerala. Strategies such as infrastructure development regarding accommodation and supporting facilities have to come from the private sector, based on the tourism policies of Kerala. Tourism infrastructure projects are proposed to be implemented primarily through private investments. Though certain incentives and subsidies are being offered for tourism projects, the policy, in the long term, is to phase out financial incentives and concessions, and attract investments based on merits, by providing the infrastructure and facilities. Further, even basic infrastructure projects are to be implemented with an increasing degree of financial participation by non-government entities. Despite these, our interviews with entrepreneurs show the lack of investor-friendly atmosphere in Kerala's tourism sector, as opposed to the claims in the policy documents.

\subsection{Current scenario}

The state government' s total plan expenditure on tourism increased from 86.3 crore in $2006-07$ to 230.45 crore in 2014-15, as shown in Figure 1. The government spending on tourism in Kerala is one among the highest in India. 


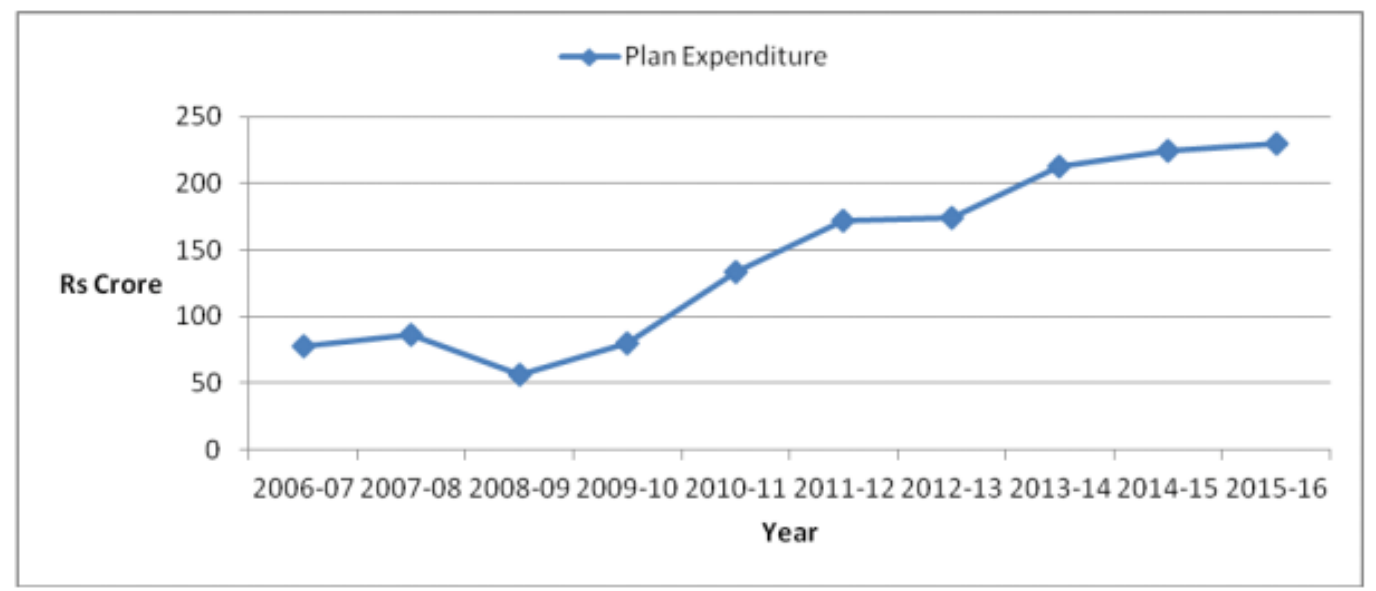

Figure 1: total plan expenditure on tourism from 2006-2016

The component wise plan expenditure from 2007-08 to 2015-16 shows that out of the total expenditure on tourism, more than half went to infrastructure, ranging from 88 per cent in 2007-08 to 71 per cent in 2015-16. The next major expenditure was on marketing (ranging from 11 per cent to 21 per cent), followed by human resource development and other activities (ranging from 1 per cent to 9 per cent). Among the infrastructure component, however, major allocation is for general infrastructure, consisting of created infrastructure for tourism that would be implemented through various line departments with little role for the Department of Tourism, and not for basic tourism infrastructure as such. In 2007-08, out of the total plan amount of 75.9 crore allotted to infrastructure, 98 per cent went to general infrastructure that would be implemented by other line departments and only 2 per cent went to basic tourism infrastructure as such. In 2014-15, out of the total plan amount of 92.3 crore allotted to infrastructure, 90 per cent went to general infrastructure that would be implemented by other line departments and only 10 per cent went to basic tourism infrastructure as such.

According to the tourism policies of the state, the Department of Tourism should focus on the development of basic infrastructure for the promotion of new tourism products for tapping the tourism potential of Kerala, leaving the rest to private investors. However, the trends in plan expenditure Kerala Tourism - The Role of the Government and Economic Impacts 9 show that this claim is a myth, since majority of the allocations went to general infrastructure projects, which were implemented by the line departments, while the department had no role to play in their implementation.

\subsection{Strengths of Kerala tourism}

1) Excellent geographical features, extremely serene environments that attract tourists the world over - lakes, hillocks, vast coastal areas, network of 44 rivers, waterfalls, lush green paddy fields, sprawling plantations, exotic wildlife etc. Well known destination for medical tourism; both Ayurvedic centres and world class health care (modern medicine) at affordable rates. Above all, the world-famous brand, “God's own Country” as well.

2) Recognitions and awards, both from National and International agencies. Six times winner of Best Tourism state from Govt. of India.

3) Consistent increase in the number of tourist arrivals, both domestic and foreign.

4) In respect of foreign tourist arrivals, Kerala in one among the best 10 states in India.

5) One of the highest growth rates in tourist arrivals. The number of tourists arrived in Kerala in 2006 is 4.28 lakhs in 2006 as against 3.46 in 2005. (13.14\% increase)

6) About $10 \%$ share of Kerala in Indian tourism. 


\subsection{Weaknesses of Kerala Tourism}

7) The share of Kerala in Indian tourism is wavering at about $10 \%$, not increasing over the years. In 2013, it was $10.81 \%$ which declined to $8.85 \%$ in 2018 and slightly improved to $9.67 \%$ in 2019 .

8) Not among the best ten states in India in tourist arrivals (domestic), though one among the best ten in foreign tourist arrivals.

9) Gross underutilization of the excellent tourism potentialities of the state, hence there is an urgent need for scaling up of tourism initiatives for optimal results.

10) Kerala lags behind all the three south Indian states in tourist arrivals, Andhra Pradesh, Tamil Nadu and Karnataka.

11) Under-utilization of immense tourism potential, like the classic tourist attractions like House Boats, Tree Houses etc.

\section{Economic impact of the tourism industries}

Kerala is the first state in India to declare tourism as an industry. The tourism policy documents of the central and state governments claim that Kerala tourism model is one of the most liberalized tourism models with the private sector leading tourism development.

Tourism has emerged as an important sector globally, contributing to around 10 per cent of global GDP, 9.4 per cent of global employment, 7 per cent of global exports and 30 per cent of service exports . International tourism receipts earned by destinations worldwide surged from USD 2 billion in 1950 to USD 1260 billion in 2015. International tourist arrivals worldwide also increased from 25.3 million in 1950 to 1186 million in 2015. Tourism growth is no longer concentrated in the industrial countries, as emerging markets have also developed into major players in the global tourism industry since the 1980s. Global studies have shown that the tourism sector has performed better in relatively free market conditions, where the role of the governments would be facilitators and supporters with the private sector playing a major role in tourism development.

Tourism constitutes 10 per cent of Kerala's GDP, as per official statistics, and reportedly contributes around 23.5 per cent to the total employment in the state. Despite the huge potential of the sector for contributing to economic growth and employment, global tourism studies show that the benefits from tourism in many places are overestimated. The reason includes the issues associated with the definition of tourists and the measurement of the economic impacts of tourism. The economic impacts of the estimates for tourism rest heavily on good estimates of the number and types of visitors, as mentioned in global studies on tourism. Thus, whether the contributions from tourism to the Kerala economy are commensurate with the huge investment made by the state in tourism depends on the quality of the estimates of the number and types of tourists.

\section{Socio-Cultural impact of tourism in the State}

The socio-cultural impacts of tourism have received increasing attention from researchers since the 1970s. Sociocultural impacts of tourism are the effects on host communities with direct or indirect contact with tourists and the tourism industry. These are subjective, not always apparent, and are often difficult to measure, as, to a large extent, they are indirect (Ratz, 2000). Consequently, it is essential to explore the socio-cultural transformations invoked by tourism through residents' perceptions rather than attempting to measure the actual effects.

Intercultural contact between tourists and host nationals can be regarded as a unique form of cross-cultural interaction. Tourists generally stay for a short period of time in a community, while staying at the destination, tourists interrelate with local inhabitants and the result of their interaction between two culture (host and guest) is alteration in the host persons and the host's community's living standard, value systems, labour division, attitudes, habits, thoughts, family relationships, manner, behavioural patterns, ceremonies and creative expressions. This stay has a multiple impact on local, both positive and negative, on people's way of living and on the social environment. There is inconsistency amongst the social science tourism researchers as to what accurately constitutes the socio-cultural effects of tourism. 
The expectations and eagerness of the tourists can also impact on the host society. It is observed that the most notable effect of tourism on traditional values and culture is certain social and human interactions change into the commercialization of cultural values and traditions at the destination for the purpose of earning of living. It is indicated that with the introduction of tourism at large-scale in developing countries, goods and/or services that used to be part of people's individual and social lives have been commercialized and presented as commodities. Commercialization means that services which were earlier provided free come to be offered mainly for money, thus a value system based on moral values comes to be changed by based on money. Interpersonal interactions are altered into a resource for monetary term and the share of social relationship decrease. Intercultural come across between tourists and hosts require to be differentiated according to the phase of tourism progress in which they take place and the type of tourist involved. Tourism tends to become challenging as the numbers of tourists increase. The level of adulthood of the tourism industry, the degree of dependence on tourism and the patterns of relations between tourists and resident all make a payment to its sociocultural effects and are all related to tourist 'type'.

Apart from above studied negative impacts has been seen with tourism development but it can be panacea for developing in removing their economic, social and environmental problems. Tourism can work as a remedy for social development at the destination where their society is not developed in the sense of education, employment, living standard, way of living of life, women empowerment, international awareness etc. One of the major impacts of cross-cultural communication is that can encourage awareness between the host and guests. Residents are learned about the outside world without leaving their homes, while travelers know about different culture.

\section{Prospective solutions for correcting negative impacts of tourism}

1) Community Participation in Business and Decision making

2) Local should be more benefits gainers of the sector.

3) Control over tourism business through ownership,

4) Local administration and formal inclusion of local community.

5) Socio- economic impact consideration in policy making

\section{Environmental Effects of Tourism}

Tourism is travel for predominantly recreational or leisure purposes. According to The World Tourism Organization definition tourists as people who "travel to and stay in places outside their usual environment for not more than one consecutive year for leisure, business and other purposes not related to the exercise of an activity remunerated from within the place visited". In context of globalization international tourism is the largest and most rapidly expanding industry in the world. Many of the most popular tourist destinations depend heavily on the natural environment for their appeal. According to the World Tourism Organization, 698 million people travelled to a foreign country in 2000, spending more US\$ 478 billion. International tourism receipts combined with passenger transport currently total more than US\$ 575 billion - making tourism the world's number one export earner. Tourism involves the movement of people from their homes to other destinations and accounts for about $50 \%$ of traffic movements; to give an indication, the ICAO reported that the number of international air passengers worldwide rose from 88 million in 1972 to 344 million in 1994. From 594 million international travelers in 1996, numbers are forecast to leap to 702 million by next year, and from 698 million international travelers in 2000 , numbers are forecast to leap to 1,018 million by 2010 and 1.6 billion by 2020 . One consequence of this increase in air transport is that tourism now accounts for more than $60 \%$ of air travel and is therefore responsible for an important share of air emissions and the role of air travel within the industry is also likely to expand and cause considerable environmental damage and to have knock-on effects on the tourism industry itself. Air pollution from tourist transportation has impacts on the global level, especially from carbon dioxide (CO2) emissions related to transportation energy use. And it can contribute to severe local air pollution. Some of these impacts are quite specific to tourist activities. Currently, aircraft account for around 3\% of all emissions globally. The International Panel on Climate Change expects this to increase by up to $7 \%$ by 2050 . Because emissions from other sectors are also expected to increase, this figure masks the increase in real terms: the actual tonnage of carbon emitted, driven 
by air traffic increase of $5 \%$ per year, will increase by over $75 \%$ by 2015 . Thus, the problem of environment is growing that has to be brought down to achieve sustainable development.

Vijaya Kumar and R.Babu (2008) identified that the unstructured development of tourism has brought out adverse impacts on the natural environment which is being the foundation for the tourism industry in Munnar. Over construction (unauthorized) on the rolling grass land ecosystem, lack of waste management techniques, deforestation, maximum utilization of resources, the profit motive, absence of holistic approach of tourism infrastructure development and land use pattern, lack of awareness among the tourism promoters, lack of visitor management technique, exceeding carrying capacity and disappearance of species diversity etc. adversely affect the aesthetic value and quality of this mountain environment that raise the question of sustainable development of tourism in this hill station.

Raju. G.P (2009) remarked that forest and marine habitats are being destroyed and some of the wildlife they contain is being driven to extinction under the pressures of hunting, logging, agriculture and fishing. Where areas have been officially reserved for nature conservation, many developing country governments lacks sufficient funds to manage and protect them. These areas are being destroyed because they are not fully valued for their role as nature's generic reservoirs of the World's biological resources.

Conservation of natural resources is one concern, but the immediate concern is to tackle the harm caused by the increasing number of tourists. Environmentalists have insisted on solutions like burning or burying of paper and taking away non degradable polybags to ensure proper disposable of wastes. But such solutions are always easy to suggest and difficult to implement. Even the children there are taught from an early age to keep their surroundings clean, and they don't hesitate to pick up the odd piece of garbage on the road and put it in the bin. This realization and seriousness are the need of the day. If this can be achieved, then we sure will be able to preserve Kerala's rich tourism from degradation.

\section{Challenges faced by the tourism industry}

The foregoing analysis of the growth of tourism in India shows that although the industry has registered an allround substantial development in the country during the last two-three decades, most of the potential, for its growth has not yet been exploited and much more is left to be desired. The limited, and rather unsatisfactory, growth of this industry in our country has been due to a number of problems it is beset with and various difficulties it has been facing. The important factors, which have limited the growth of tourism in India, are mentioned below: Inadequate airline capacity, particularly during the peak tourist season, bad conditions of our airports, delays in getting the bookings, flight cancellations and delays render air travel in India nightmarish for foreign tourists.

- Due to appalling conditions of traveling by trains, in India tourists prefer to avoid unless unavoidable.

- Lack of hygienic and comfortable accommodation for the tourists, in general, but reasonably good accommodation for low spending middle class tourists in particular, render tourism unattractive. Absence of motel hampers the smoothness, of long-distance travels.

- There is absence of an up-to-date information systems with quick retrieval facilities causes inconvenience to tourists.

- Another major factor inhibiting the growth of tourism is the seasonality of the industry with the busy season being limited to six months from October to March and heavy rush in November and December.

- Lack of an integrated tourism promotion program during the five-year plan periods has hindered the growth of tourism.

- Indifference of many states and union territories to tourism, which has not yet been accorded industry status by them, is another factor limiting its growth.

- Next factor is the failure of the mandarins of tourism to quickly adopt to the changing environment, for example the temporary closure of Jammu and Kashmir to tourists and socio-political and religious agitations 
in other northern states of the country rendering them unattractive to tourists, by developing and promoting alternative tourist destinations in South India.

- A lukewarm attitude towards the domestic tourism due to the emphasis placed by the authorities on foreign tourism has been another limiting factor.

\section{Public Private Partnerships (PPP) for Sustainable Tourism}

In the modern day economic scenario where large infrastructure in industrial clusters and urban centers is driving business and services, 'social-economy' enterprises, or the 'third' sector, aim to check unsustainable imbalances in growth, both regional and demographic that can often arise out of differences in 'skills' and 'scale', and this is the primordial thought around which sustainable tourism models are structured, striving to ensure 'cultural and environmental preservation' in the backdrop of 'infrastructure and income augmentation'. Companies that adopted environmental, social and governance policies in the 1990s outperformed those that did not. The outperformance is stronger in sectors where the customers are individual consumers, companies compete on the basis of brands and reputation, and in sectors where companies' products significantly depend upon extracting large amounts of natural resources (Robert G. Eccles, 2011, 2012). Thus, it comes as no surprise that there is an increasing emphasis on fully integrating the ethos of sustainability into all forms of tourism - mainstream or offbeat, with dedicated emphasis on 'green' and 'local' supply chains. There are certain institutional and regulatory aspects that cannot be expanded beyond the Government due to social and governance considerations, including developing and approving tourism policy and strategy, contracts for major infrastructure projects including connectivity, grant project approvals, permits and licenses, evaluate/ monitor contracted services, approve payment for contracted services, but it is difficult for the administration to move beyond this domain full-fledged into creating and managing tourism enterprises. While there are certain instances where the Government ventures into creating and running its own infrastructure, recent policy decisions including divestment of Government owned hotels have shown the Government's intent to restrict its role to overall governance and trunk infrastructure development and let the private sector work towards creating and managing specific tourism infrastructure, products and enterprises. In a burgeoning economy, Public Private Partnerships are essential tools to ensure that stakeholder engagement, especially Government and large enterprises, shift from delivering services directly, to service management and coordination, entrusting last mile implementation to the local community. Not only are PPP structure more amenable to structured funds and sustainable finance, but tourism is also one of the sectors where this 'social' aspect of PPP is omnipresent, with focus on community enterprises that can deliver the 'entrepreneur-owner-manager' model at the grassroots.

Large corporate organizations, especially the hospitality conglomerates that offer 'authentic' and 'traditional' experiences to their clients, have an important role to play here. Not only can they help develop quality tourism products for the local communities and hone their skills, but the long-term vision should also be to integrate these as a part of their own product portfolio. We need an effective policy mechanism that can ensure this Value Chain Linkage in the short to medium term. One possible avenue is channelizing CSR spending from the hospitality sector into the development of skills and markets for community tourism ventures. The synergy between the public sector and private sector has been a major force in stimulating tourism competitiveness in a number of countries at National, State and Local levels. Comprehensive development of tourism is best possible if created jointly by Government, private sector and local community. PPPs enable the public sector to benefit from commercial dynamism; the ability to raise finance in an environment of budgetary restrictions, innovations and efficiencies harnessed through the introduction of private sector investors who contribute their own capital, skills and experience.

\section{Private Sector Participation}

Tourism sector, globally as well as in India, is largely driven by the private sector, and while Governments can lay the broad policy framework and placeholders for the triple bottom line approach that defines sustainability, the private sector has to take the lead in creating business mechanisms that work closely with local communities and 
are cognizant of the need to conserve fragile ecosystems, and through these collaborative mechanisms to create profitable business models. However, from a financial standpoint, investment in sustainable tourism is as much impact focused as return oriented. It requires a steady, long-term investment and owing to its social benefits, is commonly a part of many impact investing portfolios. Also, many businesses remain too small for investment. Often, local and indigenous communities with interest in tourism have trouble finding the support they need to start businesses. Investors and development banks also have lower interest and a limited ability to be able to support many small operations, since they often have to work more closely with their investments in order to ensure proper practices are being used. However, sustainability led measures can deliver faster Return on Investment with strict monitoring and evaluation.

For instance, energy and water efficient infrastructure can pay for itself through the energy-cost savings of greening operations (Tazawa 2017). There is a range of options for the use of outsourcing, which include concessions, leases, licenses and permits. Within concessions, there are forms that have different implications for the level of capital investment and maintenance that the concessionaire takes for responsibility for. These include Build Operate and Transfer (BOT), where the concessionaire is responsible for the construction costs and activities, their operation, and then transfers them to the Government at the end of the concession period. Other forms include Rehabilitate Operate and Transfer (ROT), Design-Build-Operate (DBO), and Maintain and Operate. The Government can include performance bonds in contracts to ensure funds to invest in capital repairs and maintenance during the contract. The figure below demonstrates the decision-making process for choosing the appropriate contracting mechanism. Investing in sustainable tourism also requires 'balancing out' the differences in planning horizons of various stakeholders involved. It is important for the private sector to recognize and follow the Equator Principles to underline the benefits associated with identifying, assessing and managing social and environmental issues. While signatories recognize their need to make profits, they also state that their "role as financiers affords (them) opportunities to promote responsible environmental stewardship and socially responsible development".

\section{Creating Sustainable alternates}

\subsection{Inclusive and sustainable economic growth}

Tourism is one of the driving forces of global economic growth, and currently accounts for 1 in 10 jobs worldwide. By giving access to decent work opportunities in the tourism sector, society- particularly youth and women- can benefit from enhanced skills and professional development. The sector's contribution to job creation is recognized in target 8.9 of Sustainable Development Goals, "By 2030, devise and implement policies to promote sustainable tourism that creates jobs and promotes local culture and products".

This would require cultivating a favourable business environment for communities, many of whom would require intensive capacity building to create an understanding of formal economies to initiate and manage their own business enterprises. Creating this bridge through institutional and industrial collaborations and fostering interlinkages with other sectors are the pivotal factors determining the success of responsible tourism models.

\subsection{Social inclusiveness, employment and poverty reduction}

One of tourism's salient features is the opportunities it offers for economic activity at the local level, especially for women and youth - the sector employs higher number of women and young people than are represented in the overall global workforce. While not all forms of tourism can directly alleviate poverty, their contribution can still be felt in poverty reduction given the low skills requirements for entry-level positions and the prospects it offers for small-scale entrepreneurs to pursue new activities or formalize existing micro ventures. The multi-sectoral and complex nature of tourism value chain presents significant opportunities for generating backward and forward linkages which can engage local micro-, small- and medium-sized enterprises (MSMEs). 


\subsection{Resource efficiency, environmental protection, and climate change adaptation and mitigation}

While tourism's multi-faceted social and economic impact has the potential to improve living indices at the bottom of the pyramid, we have to be cognizant of the present context the increasing number of air travelers, large hotels with massive energy consumptions and other modern-day amenities that putting a strain on natural and cultural resources and also contributing to climate change.

\subsection{Respect for cultural values, diversity, and heritage}

The relationship between heritage and tourism is two-way:

- Heritage offers tourists/visitors and the tourism sector destinations, products and recreational opportunities.

- Tourism offers heritage sites the ability to realize community and economic benefits through sustainable use

Heritage and Cultural tourism are growing at an unprecedented rate and now accounts for around $40 \%$ of global tourism. New opportunities exist to strengthen links between tourism and other creative industries, including music, the performing arts, design and cuisine. Recently, significant attention has been paid to the growing significance of food tourism14, as well as the role of contemporary culture in urban regeneration and renewal linked to tourism15. Given the rapid growth of the creative industries - with trade in creative goods increasing by $8.6 \%$ per year from 2003 to 201216 - the time is ripe to link contemporary culture and creative cultural activities to tourism. Not only would this enrich tourism offer, but it can also help to revive urban areas, facilitate host-guest interaction, and promote local creativity.

It is an undisputed fact that tourism aids the revival of traditional activities and customs and provides an economic incentive to communities to preserve and showcase them. However, prolonged unsustainable use can lead to not only lead to physical damage to the sites, but also distort the social landscape of the destination if mass tourism activities become unsustainable. UNESCO's World Heritage and Sustainable Tourism (WH+ST) Program aims to integrate sustainable tourism principles into the mechanisms of the World Heritage Convention.

\section{Mutual understanding, peace, and security}

There exists a strong, positive correlation between tourism and peace. While peace and security are a prerequisite for the very existence of tourism, the transformative power of tourism - grounded upon billions of encounters that occur every day - paves the way towards dialogue, mutual understanding and tolerance, the cornerstones towards ensuring and maintaining peace. On a long-term canvas, sustainable tourism models foster and nurture economic development, democratization, social justice, education, equality, empowerment, and reconciliation, the pillars on which the prosperity and development of a society rests upon.

\section{Notable examples}

\subsection{Controlled tourism in Bhutan}

Bhutan, located in the East of the Himalayas, is known as one of the happiest countries in the world. The country remains relatively untouched by colonialism which has ensured that the people's sustainable way of life has remained intact.

Bhutan's tourism operates on the principle of "high value, low impact". This has been achieved by enforcing strict entry requirements and a daily visitor tariff. The daily tariff includes necessary expenses for the visit such as accommodation, a licensed tour guide, meals and hiking equipment. A large portion of the tariff, however, is used 
to maintain and develop the country's infrastructure, as well as contribute towards Bhutan's free health care and education.

\subsection{Community run backpackers in South Africa}

Mdumbi, a backpacker on the Wild Coast of South Africa, aims to promote "community involvement and sustainable eco-tourism". The backpacker prides itself in being fused with the amaXhosa culture of the Eastern Cape, situated deep in the heart of a traditional village.

With a number of sustainability interventions onsite such as energy efficiency, solar power and waste management, Mdumbi has a unique ownership model, with the local employees, the amaxhosa community association, and TransCape (Mdumbi's affiliated NPO) all holding shares in the business.

Mdumbi's NPO, TransCape, aims "to provide access to the resources, support, and knowledge necessary for communities to initiate the process of change towards a better quality of life." In 2017, the Backpacker was also awarded a silver prize by the World Responsible Tourism Awards for best in poverty reduction.

\section{Responsible tourism - allepey tourism development cooperative society, kerala}

When it comes to successfully implementing community-based tourism models, Kerala is one of the pioneer states in the country. Blessed with a verdant coastline and backwaters that play host to a multitude of scenic locations, it has been able to successfully create a diverse portfolio of tourism products including nature, wellness (Ayurveda), heritage, culture and cuisine. One of the reasons has been the major role that tourism has played in counterbalancing the decline in agriculture. The state has a clear policy focus towards responsible tourism and an institution setup to promote and manage the same. Alleppey Tourism Development Cooperative (ATDC) Society has been one of the earliest community-based tourism models in the country that has been running successfully for almost three decades, thereby demonstrating a model of business sustainability for local communities. Registered in 1987 under the State Cooperatives Act, the initial aim of the organization was to secure sustainable livelihoods for local communities who were increasingly finding agriculture to be unprofitable.

The state had seen success in cooperative model in areas of agricultural credits, milk marketing, cotton weaving and beedi making, and with some persuasion, the local communities were able to set up the first tourism cooperative focusing on houseboats, albeit with some challenges since there was no precedence of such models in the sector. With ATDC serving as the consolidated marketing face for all houseboat owners thereby providing scalability, the individual boat owners were responsible for the operational aspects. Boat owners were instructed to make the essential modifications in the rice boats to suit tourist needs, and credit for this was provided through an arrangement with a banking cooperative. However, no state subsidies were involved, which in part motivated the locals to ensure that their business model was a success (George 2007).

\section{Nature \& wildlife tourism - jungle lodges and resorts, Karnataka}

Through consistent conservation efforts, Karnataka has firmly established itself as the premier destination for wildlife tourism in India. A large part of the state encloses the Nilgiri Biosphere Reserve, containing 5 National Parks and 25 Wildlife Sanctuaries (of which 7 are bird sanctuaries), and this large swath of natural area provides a plethora of opportunities for nature-based tourism activities. One of the earliest examples of PPP in tourism, Jungle Lodges and Resorts (JLR) was established as Joint Venture between the Government of Karnataka and Tiger Tops Jungle Lodges way back in 1980 with an aim to promote eco-tourism, wildlife tourism, adventure tourism and various outdoor activities like trekking, camping, white water rafting, joy fishing etc., that are non-consumptive components of eco-tourism and help in environment conservation. Although Tiger Tops withdrew from the partnership in 1987 and sold its share to the Government, the brand continued to flourish today is one of the best examples of a Government led institution working at the efficiency levels of the private sector. The resort today has a healthy mix of inbound as well as domestic tourists, majority of them highly educated with a deep-seated appreciation for nature. Since inception, it has now expanded its footprint across Karnataka to 18 resorts and 2 heritage hotels each with its own distinctive characteristics, and a remarkable degree of consistency in positive 
consumer feedback and adherence to policies of local employment and procurement that fits into the overall model of sustainability.

\section{Create central repository of land banks:}

Availability of suitable land is one of the main concerns for investing in tourism projects, especially when it comes to sustainable tourism infrastructure in fragile areas. The states need to develop land bank outlining the land parcels available for tourism projects, which are made accessible over an interactive web platform with the support of Ministry of Tourism. This will enable investors to assess the preliminary viability of their project's basis the nature of land parcel/ select the appropriate land parcel suitable to the proposed project.

\subsection{Incentivize private sector participation}

Government/(s) should incentivize private players to invest in unserved/ under-served tourism projects. The incentive pattern can be friendlier for attracting more innovative tourism projects vis-à-vis run-of-the-mill projects. For instance, interest subvention scheme can be introduced for small tourism projects like community homestays, tour operators, RO-RO and boat operators. Additional incentives, like additional interest subvention post COD, can be provided to projects (incl. new Hotels and resorts) at tourist destinations with limited tourist facilities and connectivity.

\subsection{Tourism Specific Ease of Doing Business (EoDB) Rankings}

Ease of doing business Tourism State Rankings' can be introduced by the Ministry of Tourism and NITI Aayog with comprehensive parameters for assessment of State initiatives. Currently, there is a dearth of data pertaining to sustainable tourism, and the tourism ministry can introduce a standardized format for collection and publishing of tourism data and statistics across states and districts to facilitate easier decision making by investors and also measure impact of initiatives of various states and other stakeholders.

\subsection{Reduce GST on Homestays}

Currently, hotel rooms with rents more than INR 1,000 attracts GST of $18 \%$ on homestays across the country. Prior to GST, a service tax of $8 \%$ was levied on homestays. This was applicable only on accommodation while food and other services were exempted. However, GST is applicable on the entire bill, including food and other services. This has resulted in financial burden on small homestay owners, and hence needs to be rationalized.

\subsection{Sustainable Tourism Authority (STA) under proposed National Tourism Board (NTB)}

The Ministry of Tourism is already working on an institutional structure to set up a National Tourism Board as an autonomous organization under the Government to implement policy instruments. A Sustainable Tourism Authority (STA) can be institutionalized under this body to work with other ministries and institutions on sustainable tourism.

\subsection{Promote Smart and frugal infrastructure}

As we expect sustainable tourism models to uplift rural communities, creation of modern infrastructure will be pivotal towards attracting tourists to offbeat locations. Currently, the minimum project cost for tourism projects to qualify for infrastructure status is INR $200 \mathrm{Cr}$, which is under consideration to be lowered to INR $50 \mathrm{Cr}$. However, if this entry barrier can be further lowered, or a separate incentive scheme can be carved out for smaller projects, it will encourage private players to invest in rural infra like homestays.

\subsection{Technology \& digitization}

Today's technologies give us clear insights and easy to use tools to advance sustainable and inclusive growth and go far beyond cashless transactions and reservations. Data analytics can help small entrepreneurs establish credit to scale their business, or insights into consumer spending trends which can further facilitate municipalities on crowd management and urban planning. Enabling a cashless ecosystem for tourists, introducing value added 
products like Incredible India Travel Card, application of GIS and emerging technologies, like Artificial Intelligence (AI) are some areas where India has knowledge expertise and manpower advantage.

\subsection{Tourism startups}

New age entrepreneurs have demonstrated the power of frugal innovation and lean startups in transforming the travel industry. Online aggregators and travel tech startup are redefining supply chain models and putting the consumer in the driver's seat. The Government's Startup India campaign can provide a platform to link aspiring youth, especially in rural and remote areas, looking for opportunities to start their own tourism enterprises with new age tech startups to create sustainable local economies.

\subsection{Skill development and community entrepreneurship}

While infrastructure is one part of the puzzle, training communities at the same time is the other essential aspect. This would involve a wide range of skills ranging from soft skills to technical aspects pertaining to sustainable utilization of resources, waste management, and business management skills including financial management, marketing and promotion.

\subsection{Carrying capacity management}

In order to ensure sustainable utilization of resources and to avoid any irreversible damage to the environment or communities, a nationwide survey of carrying capacity needs to be undertaken basis which location-specific action strategies can be formulated to implement the Sustainable Tourism Criteria for India (STCI).

\section{Conclusion}

In order for the tourism development to contribute to economic development as well as to meet other needs of the society and the environment, it is necessary to accept the concept of sustainable development at all levels of government and to establish tourist. Balanced, rational and effective management of resources that will enable further social, economic and cultural development of the given destination may lead to long-term growth and development, improvement of quality of tourist experience which will result in a satisfied tourist who is offered a complex product.

There are numerous issues and problems that the tourism industry faces. Including sustainability in the picture, the problems become more complex, involve multiple stakeholders, and are outcomes of past actions that were undertaken to address the problem.

The local government, in partnership with the local communities and private sector, must design and enforce these policies. These may be difficult in the beginning but as far as sustainability is concerned, the long-term benefits outweigh the short-term costs. For this to be guaranteed, policies must go beyond generating not only growth in terms of tourist arrivals that often undermine carrying capacities of destinations, but also strategic plans that foster environmental sustainability, involve local communities, and ensure profit generation.

\section{References}

1. UNWTO, Tourism and Poverty Alleviation. Madrid: United Nations World Tourism Organization (2002)

2. Dogan H.Z., Forms of Adjustment: Sociocultural Impacts of Tourism, Annals of Tourism Research (1989)

3. Jafari J., Understanding the Structure of Tourism, in: AIEST, Cost and Benefits of Megaevents, St. Gallen (1982)

4. Graburn N., The anthropology of tourism, Annals of Tourism Research, 10(1), 9-33 (1983)

5. Ritchie B.J.R. and Zins M., Culture as a determinant of the attractiveness of a tourist region, Annals of Tourism Research (1978)

6. Cohen E., A phenomenology of tourist experiences. Sociology (1979)

7. Pearce P., Tourists and their hosts: Some social and psychological effects of intercultural contact. In S. Bochner (Ed.), Cultures in Contact: Studies in Cross-cultural Interaction, Oxford: Pergamon Press (1982)

8. Boissevain J., The impact of tourism on a dependent island: Gozo, Malta, Annals of Tourism Research, (1979)

9. Petit-Skinner, Tourism and acculturation in Tahiti, In B. Farrell (Ed.), The Social and Economic Impact of Tourism on Pacific Communities, Santa Cruz: Center for South Pacific Studies, University of California, Santa Cruz, (1977)

10. Crandall L., The social impact of tourism on developing regions and its measurement, In J. R. Ritchie and C. Goeldner (Eds.), Travel, Tourism, and Hospitality Research: A Handbook for Managers and Researchers, New York: John Wiley and Sons, (1987) 
11. Ryan C., Recreational Tourism: A Social Science Perspective, London: Routledge, (1991)

12. De Kadt, E., Social Planning for Tourism in the Development Countries, Annals of Tourism Research, (1979)

13. Smith V., Hosts and Guests: The Anthropology of Tourism, 2nd ed., University of Pennsylvania Press, Philadephia (1989)

14. Dower M., Tourism and Conservation, Working Together, Architect' Journal 166, 941-63 (1974)

15. Grünewald R., Tourism and cultural revival, Annals of Tourism Research, 29, 1004-1021 (2002)

16. Pearce P.L., The Ulysses factor: evaluating visitors in tourist settings, Springer-Verlag, New York. (1988)

17. Stein T.V., Anderson D.H. and Thompson D., Identifying and managing for community benefits in Minnesota State Parks, Journal of Park and Recreation Administration. 17(4), 1-19 (1999)

18. Delamere T. and Hinch T., Community festivals: Celebration or sellout. Recreation Canada, 52(1), 26-29, (1994)

19. Sebastian L.M. and Rajagopalan P., Socio-cultural transformations through tourism: a comparison of residents' perspectives at two destinations in Kerala, India, Journal of Tourism and Cultural Change, 7(1), (2009)

20. Dhariwal R., Tourist arrivals in India: How important are domestic disorders?, Tourism Economics: The Business and Finance of Tourism and Recreation, 11, 185-205, (2005)

21. Shukla Arti and Singh Neetu, Constraint of Family Structure in Youth Progress: A Study of Urban Slum of Lucknow District, India, I. Res. J. Social Sci., 1(2), 6-9 (2012)

22. Gabriel Simon Thattil and NimiDev.R, (2005), "Kerala perspective on an All-in-one Tourist Destination", In Sarangadharan.M and Raju.G, (Eds), Tourism and sustainable economic development, New Centaury Publication, New Delhi, p. 235-236.

23. http://spb.kerala.gov.in/EconomicReview2016/web/chapter09_04.php

24. https://www.cppr.in/centre-for-comparative-studies/kerala-tourism-the-role-of-the-government-and-economic-impacts

25. https://shodhganga.inflibnet.ac.in/bitstream/10603/4882/14/14_chapter\%208.pdf

26. Dr_Manoj_CUSAT_Tourism_in_Kerala_Saaransh_Vol_1_No_2_Jan_2010_PP_78_82.pdf

27. Sociocultural Impacts of Tourism on Residents of World Cultural Heritage Sites in China. 